mode of growth; the angles of crystalloids are also probably somewhat variable. The crystalloids being chiefly regular and rhombohedral forms, some are compounds containing metalschiefly magnesium, calcium, barium-others are free from metals. The growth is connected in a definite manner with the crystal line form; the forms of the regular crystalloids remain unchanged, while the rhombohedral crystallo ds undergo changes in their angles, the maximum growth being in the direction of the principal axis. The growth and solubility of the crystalloids are not equal throughout; they increase from without inwards, so that in dilute reagents the growth or the solution begins in the middle. The crystalloids are also frequently distinguished, like starch granules, by layers of unequal growth.

HERR BALlo states in Berliner Berichte that if camphor be heated with a quantity of spirit of wine, containing from 36 to 65 per cent. ethylic alcohol, such that some of the camphor remains undissolved, fusion of the camphor occurs on the surface of the alcohol, and the melted camphor either floats on the surface of the alcoholic solution, or sinks to the bottom according to the specific gravity of the liquid.

IN reference to the observations of Hantefeuille and Chappuis regarding "pernitric acid," recently mentioned in these Notes, the following details may be of interest. If a perfectly dry mixture of oxygen and nitrogen is uzonised, and the absorption spectrum of a layer about two metres long of this mixture is observed, certain fine dark lines are noticed in the red, orange, and green, in addition to the characteristic absorption bands of ozone. These lines are not exhibited by nitrogen, nitrous anhydride, nitrogen tetroxide, or nitric anhydride, when sub. mitted to the action of the electric discharge. If the gas which exhibits the new lines be conducted through water, the water acquires an acid reaction, and the ozone bands alone remain in the spectrum. If the gas be heated to redness the spectrum of nitrogen tetroxide appears. If the gas be allowed to remain at ordinary temperatures the new lines gradually fade away; after tw enty-four to forty-eight hours they have entirely disappeared; the spectrum of nitrogen tetroxide becomes gradually more prominent, and reaches a maximum after a few days. The same lines are noticeable in the absorption-spectrum of the gas produced by the action of the electric discharge on a mixture of nitrogen tetroxide and oxygen. The authors conclude that the newly-observed lines are due to the presence of an oxide of nitrogen containing relatively more oxygen than $\mathrm{N}_{2} \mathrm{O}_{5}$, i.e. to the anhydride of "pernitric acid."

\section{METEOKOLOGICAL NOTES}

IN a paper on the "Marche des Isotherms au Printemps dans le Nord de l'Europe," Prof. Hildebrandsson of Upsala Meteorological Observatory has struck out a fresh line of inquiry and produced results at once of great scientific, and practical value. In a series of five maps he shows the advances with season northwards over North-Western Europe of the isotherms of $32^{\circ} \cdot 0,37^{\circ} \cdot 4,42^{\circ} \cdot 8,48^{\circ} \cdot 2$, and $53^{\circ} \cdot 6$ respectively, the isotherms being thus $5^{\circ} .4$ (or $3^{\circ} \circ \mathrm{C}$.) apart. On January 15 the isotherm of $32^{\circ}$. 0 proceeds along the south coasts of the Black Sea and thence westwards to near Lyons, from which point it strikes northwards, passing into the North Sea at Gröningen, and skirts the west of Norway as far as Christiansund. The progress northwards and eastwards of this isotherm at the subsequent fortnightly epochs is extremely instructive, the advance northwards over the plains of Russia being manifoldly more rapid than its advance over the south-west of Norway. By May $I$ the mean temperature of the whole of North-Western Europe has risen above $32^{\circ} \cdot 0$ except a small portion from the North Cape to the White Sea. In the height of summer the isotherm of $53^{\circ} \cdot 6\left(12^{\circ} \mathrm{C}\right.$.) reaches its northern limit, and then includes the whole of Europe except a thin slice of Norway from Vardö to the Lofoden Isles. Since on April 15 this isotherm skirts the southern shores of the Black Sea, its advance northwards is much more rapid than that of $32^{\circ} \circ$. Specially instructive is it to note the influence of the various seas ard mountain ystems on the seasonal advance of the different isotherms. An interesting table is given showing the time talen by various natural phenomena to advance a degree of latitude northwards 'along the shores of the Baltic. The flowering of plants takes $4 \cdot 3$ days in advancing over a degree of latitude in April, $2^{\circ} 3$ days in May, ${ }^{\circ} 5$ days in June, and 0.5 days in July; the ripeninge of fruits generally 1.5 days; and the fall of forest leaves $2 \cdot 3$ days. Hence the phenomena are propagated with the greatest rapidity when the temperature approaches and reaches the annual maximum.

SOME months ago Miss Ormerod made a present to meteorologists of some value in her book entitled "The Cobham Journals," which gives an appreciative, well-written, and in some respects novel and ingenious account of the meteorological and phenological observations made by the late $\mathrm{Mis}$ Caroline Molesworth at Cobham, from 1825 to 1850 . For each of the years complete tables are given of temperature, rainfall, and wind, which include also a comparative table for temperature and rain for Chiswick, taken from Glaisher's discussion of the Chiswick meteorological observations from 1826-69. Along with these tables are printed full notes setting forth the main features of the weather of each month, the month being divided into more or fewer sections, according to the number of types of weather which prevailed; and a detailed account of the accom. panying phenomena of vegetation and animal life. In the general summary appended to the work the bearings of weather on plant and animal life are more specially dealt with, and a valuable table is given showing the dates of the flowering of plants, the leafing of trees, the ripening of fruits, and the arrival of birds. What is much to be admired in the work is the modesty, conscientiousness, and earnestness everywhere manifest, and these qualities of the scientific worker, it may be added, equally characterise the admirably-planned and worked scheme of Observations of Injurious Insects the author is now conducting so successfully.

A $\mathrm{T}$ the General Meeting of the Scottish Meteorological Society held on Friday last, Mr. Buchan read a paper on the atmospheric pres:ure of the British Islands, based on the observations of the last twenty-four years at about $3 \mathrm{co}$ stations. The mean pressure of these Islands taken as a whole is very nearly $29^{\circ} 900$ inches, this isobar crossing the country from Galway to Newcastle. From this it rises southwards to 29.983 inches in the ( hannel Isles, and falls northward to $29^{\circ} 780$ inches at North Unst in the extreme north of Shetland, there being thus a difference of about two-tenths of an inch of mean pressure between the extreme south and north. As regards individual stations the annual monthly maximum is attained in May, to the north of a line drawn from the mouth of the Shannon to the Wash, and thence round to Colchester, and the excess of this month's pressure is the greater as we advance north-westwards to the Hebrides; it is greatest in July over the extreme south of Ireland and the extreme south-west of England; but elsewhere the highest monthly mean is in June. The maximum in May over the whole of the northern portion of these Islands is connected with the maximum during the same month over arctic and sub-arctic North Atlantic, and regions adjoining, and the maximum in July over the south west is connected with the high pressure which obtains in this month over the Atlantic between Africa and the United States. The July pressure of the south-east of England is lowered from its proximity to the Continent, where pressure falls to the minimum in July. The mean monıhly minimum occurs in January everyw here to the north of a line from Galway to Berwick; in March to the east of a line from Hull to Osborne; and in October over the rest of England and Jreland, which thus includes the larger portion of the British Islands. Of these depressions in the annual march of the pressure, by far the largest is the January one, which in the Outer Hebrides falls to 0.080 inch below the mean of any other month. It is there accordingly where the great diminution of pressure in the north of the Atlantic during the winter month is most felt. The greatest difference between the extreme north and south, amounting to nearly $0^{\circ} 400$ inch, takes place in January, and it is in this month when the isobars lie most uniformly from west-south-west to east-north-east, thus giving the gradient for the south-w esterly winds which prevail in this season. The least variation occurs in May, the extremes being $30^{\circ} \mathrm{OO} 2$ inches in Scilly in the south, and $29^{\circ} 906$ inches at North Unst in the nortb, being thus only a fourth part of the difference which obtains in January. The greatest divergence from parallelism among the isobars occurs in July, where the arrangement somewhat resembles a fan with the hand part in the west of Ireland, and the lines opening out to their greatest extent in the east of Great Britain-adisposition of the lines due to the position of Great Britain between the high pressure which at this season overspreads the Atlantic to the south-west, and the low pressure which is so characteristic a feature of the meteorology of the old Continent in summer.

THE temperature of January last was of a character sufficiently striking and unusual as to call for a permanent record in ou 
pages. I ower mean temperatures of particular months have occurred previously in Shetland, Orkney, and the extreme north of Caithness and Sutherland, January, 1867, having been colder in these northern regions. Other months, notably February, 1855, were as cold as, or colder than, January last over England generally except its north-western counties. But in this latter district and over the whole of the rest of Scotland January was colder than any month on record, yoing back for the different districts on observation; which extend over periods varying from 24 to II 8 years. The mean temperature fell below that of any previously recorded month in varied amounts up to $4^{\circ} \mathrm{O}$, this excessive degree of cold being experienced chiefly in the upper narrow valleys of the interior of the country, such as Lairs in Sutherland, Upper Deeside, and Tweeddale, and the uplying valleys of the Cheviots. The greatest absolute cold occurred on the nights immediately preceding the great London storm of the 18 th, the lowest, so far as the facts have reached us, being - $16^{\circ} \circ \mathrm{O}$ near Kelso; $-15^{\circ} \circ \mathrm{O}$ at Stobo Castle in Peeblesshire; - I $3^{\circ} \mathrm{O}$ at Paxton House near Berwick; - $\mathbf{I} \mathbf{I}^{\circ} \mathrm{O}$ at Lairg, and Thirlestane Castle near Lauder; and $-8^{\circ} \cdot 0$ at Milne Graden near Coldstream. This depression of temperature thus equalled that of the memorable night of December 4,1879 , when it fell, at Springwood Park near Kelso, to - $16^{\circ} \circ$, which is abso lutely the lowest authentic temperature that has been recorded in Great Britain since thermometers came into use, leaving out of view as incomparable and misleading all observations made with exposed thermometers. In Scotland, the mean temperature of each of the five months ending with February was under the average, the depression being greatest just where as stated above the cold of January was greatest. The mean temperature of these five months was $5^{\circ} .6$ under the average in West Perthshire, $5^{\circ} \cdot 0$ at Lanark, $4^{\circ} \cdot 5$ at Thirlestane Castle, Braemar, and Culloden, and about $3^{\circ} \mathrm{O}$ in the west from North Unst to the Solway Firth. In South Britain, the mean temperature of this period did not fall so low owing to the milder weather there during November and Decenber. The snowstorms of this winter are, at least equally memorable, particularly the great storin of the third week of January in the south of England, and the great storm in Scotland in the first week of Marcb, when railway traffic was paralysed, many trains being buried under snow-wreaths, twenty, thirty, and even in some cases forty feet in thickness.

\section{THE OXFORD UNIVERSITY COMMISSIONERS AND THE PROFESSORIATE}

THE University Commissioners have $\mathrm{i}$-sued a revised edition of the proposed statute; on the professoriate. The scheme laid before the Hebdomadal Council last November met with considerable opposition, which re ulted in representations bein made by the Council to the Commissioners in favour of certain modifications in the duties assigned to the professors. On comparing the revised with the old proposals, it is evident that the Commissioners have become convinced that it is desirable to allow each professor a larger individual Jiberty in the mode of giving instruction in his department than was granted in the former scheme. In the General Regulations of last November Clauses 4 and 5 ran as follows:-

4. During the period of each term over which his course of lectures shall extend, and on so many days in the week as the particular regulations applicable to his chair require, he shall be ready to give private instruction to such students, being member of the university and attending his lectures, as may desire to receive it, in such matters relevant to the subjects of his lectures as may more conveniently be explained in that monner, and also to test by questions or otherwise, as may be convenie.ut, the knowledge of such students in those subjects. Such private instruction shall be open without fee to students who are members of a college out of the rcvenues of which his chair is wholly or partly endowed, and to other students on payment of such fees (if any) as the professor may require, not exceeding in number or amount the limit set by any statutes of the university in that behalf which may be in force for the time being.

5. At the end of each term in which he has delivered lectures he shall examine the students who have attended them, and shall, on the request of the head of any college, inform the college of the results of the examination as regards the student who are members of such college, and shall also, if requested, give like information to the Delegates of students not attached to any college or hall.

In the new statutes the obligation to examine the whole class is removed; but each professor at the head of a laboratory or observatory must inform the college authorities of the regularity and proficiency of students attending his department. The new general regulations run as follow:-

\section{Duties of Professors}

I. It shall be the duty of every professor in his de artment to give instruction to students, assist the pursuit of knowledge, and contribute to the advancement of it, and aid generally the work of the university.

2. Every professor shall in respect of the lectures to be given by him conform to the particular regulations applicable to his chair. He may lecture in such manner and form as he judges to be hest for the instruction of students and the advancement of knowledge.

3. It shall be his duty to give to students attending his ordinary lectures assistance in their studies by advice, by informal instruetion, by occasional or periodical examination, and otherwise, as he may jud ge to be expedient. For receiving students who desire such assistance he shall appoint stated times in every week in which he lectures.

4. At the reques: of any student who has regularly attended any course of lectures he shall certify in writing the fact of such attendance.

5. The ordinary lectures of every professor shall be open to all students who are members of the university without payment of any fee, unles; the university shall otherwise determine. But the university may, if it should deem it expedient so to do, by statute or decree authorise any professor to require payment of fees not exceeding a specified amount in respect of all or any of bis lectures or of the instruction to be given by him.

6. Every professor shall in addition to his ordinary lectures deliver from time to time, after previous public notice, a public lecture or lectures to be open to all members of the university without payment of any fee.

With regard to the manner of election to professorships and to the dispensations and leave of absence granted by the visita torial boards, little or no alterations have been made. The professoriate is divided into three schedules. With the exception of the professors of geology, mineralogy, and botany who come under Schedule B, the pr.jessors in the different departments of natural science come under Schedule $C$, to which division the following particular regulations are applicable :-

(a) The professor shall reside within the university during six months at least in each academical year, between the first day of September and the ensuing first day of July.

(b) He shall lecture in two at least of the three university terms. His lectures shall extend over a period not less in any term than six weeks, and not less in the whole than fourteen weeks, and he shall lecture twice at least in each week.

(c) The laboratory under the charge of each professor, and in the case of the Savilian Professor of Astronomy, the University Observatory, shall be open for eight weeks in each term, and at such other times and for such hours as the university may by statute determine.

Students shall be admitted to the university observatory, and to the laboratory under the charge of each professor, upon such conditions as the university shall from time to time by statute determine, and upon the terms of paying such fees, not exceeding such amount as may be fixed by any statute of the university in force for the time being, as the professor may from time to time require.

(d) Except for some grave reason to be approved by the Vice-Chancellor, the professor shall, for seven weeks in each term, and during some part of three days in each week, be ready to give instruction in the subject of his chair to such students as shall have been ad nitted to the laboratory under his charge (or in the case of the Savilian Professor of Astronomy, to the University Observatory); and such instruction shall be given in the laboratory or observatory (as the case may be) or in some class-room connected therewith.

(c) The professor shall also, at the close of each term, inform any college which may request him to do so as to the regularity of attendance and the proficiency of the students belonging to such college who have been admitted into the laboratory or observatory under his charge, and shall give like information, if requested, to the Delegates of students $\mathrm{n}$ )t attached to any college or hall.

4. The particular regulations next following shall be applicable to the several professors named in them re ipectively (that is to say) - 